\title{
CONTEMPLANDO OS DESTROÇOS DO FUTURO: A MEMÓRIA HISTÓRICA REVESTIDA DE FICÇÃO EM O CONTO DA AIA
}

CONTEMPLATING RUBBLE IN THE FUTURE: THE HISTORICAL MEMORY COATED IN FICTION IN THE HANDMAID'S TALE

\author{
Valdinei José Arboleya ${ }^{1}$ \\ Universidade Estadual do Oeste do Paraná
}

Resumo: Partindo das discussões sobre literatura, memória e história, objetiva-se, neste estudo, analisar o romance distópico O conto da Aia, [1985] (2017), de Margareth Atwood, como um gênero literário capaz de retomar vestígios da memória. Sustenta-se aqui, a associação entre memória e distopia como algo que se fundamenta no argumento de que textos distópicos são formas de retomar a tradição, problematizando riscos sociais e políticos e ressignificando as questões decorrentes do campo da formação das identidades. Assim, propõe-se, neste estudo, tecer algumas reflexões sobre os rastros do passado realocados sob a forma de ficção e ambientados em um futuro pós-apocalíptico no romance, mobilizando o conceito antropológico de valência diferencial dos sexos e o conceito de memória para estabelecer alguns caminhos comparativos entre as personagens deste romance e alguns arquétipos bíblicos.

Palavras-Chave: Literatura Comparada; Distopia; Memória; Papel feminino.

1 Endereço eletrônico: vjarboleya@hotmail.com. 
Abstract: This study seeks to analyze the dystopian novel The Handmaid's tale, [1985] (2017), by Margareth Atwood, as a literary genre that presents memory traces and articulating discussions about literature, memory, and history. The aims are to study the association between memory and dystopia based on the argument that dystopian novels are ways of resuming tradition and to problematize the social and political risks of this resumption and the cultural resignifications matter arising from it, which affect the identities formation field. In this study, we propose to make some reflections on the past traces relocated in the fiction form and set in a post-apocalyptic future in the novel, mobilizing the anthropological concept differential valence of the sexes and the memory concept to establish some comparative paths between the novel characters and some biblical archetypes.

Keywords: Comparative literature; Dystopia; Memory; Feminine role.

\section{INTRODUÇÃO}

A relação entre memória, literatura e sociedade é facilmente perceptível nos mais variados modos de produção e de circulação da obra literária. Embora seja recorrentemente associada a gêneros como romance histórico, literatura de testemunho e escritas do eu, nos quais a mobilização dessas categorias é indispensável para a leitura, em seu sentido mais amplo, a memória histórica tem sua base de assentamento na poesia épica, nas epístolas e nas narrativas populares que, de acordo com Pesavento (1999, p. 830) serviram de base para os contos clássicos, não como uma "versão do passado convincente e próxima o mais possível do acontecido um dia", mas como uma reconfiguração temporal em que a trama "busca atingir este efeito de apresentar uma versão também plausível e convincente" (PESAVENTO, 1999, p. 830).

A esta forma de reconfiguração, Candido (2000) atribui a essência da criação artística, na qual os fatores sociais se exprimem sob diversas formas de sublimação que atuam sobre os indivíduos, "modificando a sua conduta e concepção de mundo, ou reforçando neles o sentimento dos valores sociais" (CANDIDO, 2000, p. 20-21). Trata-se de um efeito do real que tanto a história quanto a literatura perfazem, mas nunca como exercício de mera subjetividade individual, pois o processo criativo nunca está completamente dissociado do 
contexto de sua produção, motivo pelo qual parece seguro afirmar que todos os gêneros literários narrativos potencializam as relações entre lembrar e narrar como quadros sociais da memória (HALBWACHS, 1990), isto é, como um exercício que se desenvolve com base no senso de pertencimento às instituições sociais as quais o indivíduo integra.

Corroborando esse senso de pertencimento, Fernandes-Prieto (1997, p. 185) chega a afirmar que "todo gênero literário é apresentado como fenômeno histórico que funciona como modelo de escrita para autores e como horizonte de expectativas para os leitores".

Ou seja, autor e leitor são abarcados por uma cadeia de representações ampla e abrangente na qual atua a literatura, que tem o poder de evocar lembranças intencionalmente projetadas no texto por um autor histórica e socialmente situado, mas que também, em face de sua natureza plurissignificativa, permite ao leitor acionar memórias particulares, independentes das que foram intencionalmente projetadas pelo autor.

A memória, sob essa ótica, é resultado dos entrecruzamentos das correntes do pensamento coletivo e, por isso mesmo, está diretamente associada à formação da identidade, pois, entretecida com a história, "procura salvar o passado para servir o presente e o futuro" (LE GOFF, 1990, p. 477). Nesse processo, cria-se um sentimento comum de pertencimento, recorrentemente matizado pela tendência à afetividade, por meio do qual acaba se evidenciando um movimento que prioriza uma lembrança que se pretende perpetuar em detrimento de outra que se deseja anular nas fontes oficiais, inclusive, na Literatura, em que o efeito do real se potencializa justamente pela dimensão estética.

\footnotetext{
2 No original: "todo género literario se presenta como un fenómeno histórico que funciona como un modelo de escritura para los autores y como horizonte de expectativas para los lectores".
} 
Como assinalado anteriormente, em romances históricos e em literaturas de testemunhos, ainda que o foco narrativo seja permeado por intenso lirismo, a relação entre história e memória e apresentação de um efeito do real são mais latentes. Contudo, a inquietação que movimenta este estudo reside na problematização dessa relação em romances distópicos: seria possível encontrar vestígios da memória na distopia?

Por acreditar que essa associação não apenas é possível, como se fundamenta exatamente sobre o argumento de que a distopia é uma forma de reavaliar os aspectos sombrios e retrógrados da história que incidiram, inclusive, no campo da formação das identidades, propõe-se, neste estudo, tecer algumas reflexões sobre os rastros do passado realocados sob a forma de ficção e ambientados em um futuro pós-apocalíptico no romance $O$ conto de Aia, do original em inglês, The Handmaid's Tale, de Margareth Atwood [1985] (2017). Acredita-se que essa releitura do passado acaba por apontar para um futuro que provoca estranhamento, desconforto e, em alguns momentos, medo, levando o leitor a ficar mais atento ao que vive na medida em que se torna capaz de identificar como este futuro se avizinha.

A abordagem aqui pretendida busca, de modo especial, focar o peso da categorização binária que Héritier (2002) classifica como valência diferencial dos sexos e estabelecer alguns caminhos comparativos entre as personagens deste romance e os arquétipos bíblicos, tomando como fio condutor o perigo do conservadorismo como corrente de pensamento política e ideológica.

\section{A DISTOPIA COMO FORMA DE RESGATAR O PASSADO}

Cenários, ambientes e tempos marcadamente otimistas ou deliberadamente pessimistas, ainda que circunstancialmente insólitos, são uma constante em narrativas utópicas e distópicas, nas quais o gênero é definido 
essencialmente pela apresentação de sociedades fictícias em que o Estado se investe de um papel totalitário e em que há a "predominância dos temas ciência e tecnologia - utopicamente, quando expresso de maneira positiva, ou distopicamente, quando usado de modo negativo" (CLAEYS, 2013, p. 163).

No que toca nomeadamente à distopia, perfilam-se narrativas caracterizadas pela delimitação de um espaço que, embora seja geograficamente situado, prescinde das referências político-geográficas conhecidas, reformulando fronteiras e redefinindo espaços físicos para ambientar um futuro projetivamente apocalíptico, e, por isso mesmo, marcadamente fictício. Trata-se de romances em que o efeito do real é afetado por um tempo que ainda não chegou e por um espaço físico que ainda não existe, mas por um ambiente hostil já experimentado, porque facilmente associado a fatos do passado histórico reinvestidos de ficção, de inventividade e de profundo negativismo. Nos termos de Fromm (2009, p. 269), as distopias "expressam o sentimento de impotência e desesperança do homem moderno assim como as utopias antigas expressavam o sentimento de autoconfiança e esperança do homem pós-medieval".

Daí a ideia de que tempo e espaço sejam elementos idealizados, cientificamente modificados, mas nunca completamente inverossímeis, porque a ambientação das narrativas deste filão desvela questões sociais já conhecidas pelo homem, como a carência de alimentos, a busca incessante pela eliminação de documentos que registram a história e a redefinição de arquivos, no sentido que Le Goff (1990) dá a esse termo, além de uma busca aferrada ao passado como tempo ideal, determinando modos de ser e de agir. Em outras palavras, busca-se supervalorizar modos de ser e de agir em detrimento das condutas sociais consideradas corretas e de formas de governos consideradas justas.

Para Claeys (2013), ao contrário das utopias, constituídas de mundos idílicos que combinam justiça social e relações éticas idealizadas, as distopias são narrativas que congregam uma descrição sombria de lugares fora da história, nos 
quais as tensões sociais são controladas pelo uso da força e do adestramento. Trata-se de um Estado que busca o poder e o nutre como um fim em si mesmo e no qual a "manipulação do passado e negação do conceito de verdade objetiva servem para confundir a minoria educada" (CLAEYS, 2013, p. 180).

Não obstante, esses cenários são ambientados por uma reflexão crítica acerca das verdades morais e dos valores sobre os quais determinada sociedade se funda, projetando uma estrutura político-ideológica que forja a memória coletiva e tenta anular a individual como uma lembrança débil que deve ser punida, justamente porque comporta um passado que se quer negado. Jacoby (2001) sugere que as distopias acabam assombrando as expectativas de futuro ao acentuar práticas sociais e culturais que tendem a ameaçar a liberdade e que, justamente por isso, é que devem ser encaradas como um exercício de análise crítica e reflexiva acerca da realidade: não falam de um dado absolutamente irreal acerca do que pode vir a ser, mas realocam temporalmente o que já foi, releem o passado, situando-o fora da história e criando, desse modo, uma projeção em que as liberdades são completamente tolhidas.

Nesse movimento, os indivíduos são subjugados pela raça, pelo gênero e pelas escolhas individuais, que são completamente planificadas, submetendo o povo a um governo totalitarista que, para Arendt (2012), age como regulador da conduta humana por meio de estruturas sociopolíticas que levam ao adestramento do comportamento e à disciplina absoluta, visando à automatização e à não transgressão da ordem.

Esse quadro tétrico não é algo puramente fictício, mas absurdamente factual, correlacionado a referenciais históricos que, longe de ficarem limitados a um passado histórico, estão cada vez mais presentes. Por essa razão, as narrativas distópicas não apenas permitem relacionar memória, história e sociedade, como abrem um novo campo de reflexão que requer a própria ampliação do conceito: a memória do que já se viu revestida do que ainda apenas se especula, o que 
parece retomar o compromisso da literatura com a sociedade e o compromisso da própria arte com a memória coletiva. Ricouer (2003, p. 25) atrela a esse movimento a questão do dever de memória, "o dever de não esquecer" que é uma forma de confrontar o esquecimento e, em decorrência, evitar a anulação dos rastros, dos vestígios do passado que permitem recompor a história sob outro ponto de vista.

Segundo Ricoeur (1997, p. 201) o rastro indica "a passagem da vida dos vivos; ele orienta a caça, a busca, a investigação, a pesquisa". Esses rastros revisitam a história apresentando outros pontos de vista, outras formas de olhar para o mesmo fato e por isso mesmo é que, para o autor, se tornam história: “dizer que ela é um conhecimento por rastros é apelar, em último recurso, para a significância de um passado findo que, no entanto, permanece preservado em seus vestígios" (RICOEUR, 1997, p. 201).

No caso das distopias, embora haja uma demarcação temporal preditiva, o que se percebe é a evidência de futuro funesto em que se entrevê o passado ao encontrar rastros do que já foi vivido, o que acaba promovendo uma fustigada sensação de incômodo. Essa sensação, como se percebe em O conto da Aia, não se limita a especulações que nascem do espírito inventivo do homem, mas a reflexões de experiências já conhecidas e repaginadas, sobretudo, por um viés político.

\section{A AIA DE GILEAD: A NOVA E MESMA SERVA DE JACOB}

A trama de $O$ conto da Aia se passa na República de Gilead, um espaço situado geográfica e politicamente no antigo território estadunidense, cujo ambiente, longe de apresentar uma sociedade futurista e cientificamente renovada, retoma as raízes puritanas do século XVII, perfilando uma cadeia hierárquica rígida em um governo totalitário. No romance, a população de 
Gilead vivencia um "encolhimento" devido a um contexto climático e ambiental tóxico que levou ao declínio acentuado da fertilidade humana: poucos homens e mulheres são férteis e são raras as mulheres que conseguem gestar e parir filhos saudáveis, sem anomalias genéticas ou que não sejam natimortos.

Em tal contexto, tudo o que é valioso pertence ao governo e uma mulher fértil passa a ser "algo" de valor acentuado, portanto, de monopólio governamental. Cumpre ressaltar que o valor não está no gênero feminino em si, mas na possibilidade de reprodução que algumas mulheres têm e tal condição não pode ser aproveitada por qualquer homem, mas somente por aqueles que ocupam posições políticas importantes. Essas mulheres passam a ser vistas como urnas depositárias que gerarão os filhos das mulheres ricas que não podem engravidar e como propriedade dos homens, o que leva à confirmação de que "a valência diferencial dos sexos e a dominação masculina são baseadas na apropriação pelo gênero masculino do poder de fecundidade do gênero feminino e ipso facto, no desfrute da sexualidade das mulheres" (HÉRITER, 2002, p. 199).

No romance, essas mulheres passam a ser denominadas como aias e vivem como propriedades do governo, desempenhando uma função política: reproduzir filhos para a pátria. O sentido original do vocábulo aia - ama de companhia, preceptora encarregada da educação doméstica de crianças de famílias abastadas - passa a ser utilizado para designar uma serva responsável pela reprodução humana. São mulheres que recebem um tratamento diferenciado, têm o corpo todo coberto por uma veste vermelha e a cabeça coberta por uma toca branca que visa esconder a sensualidade que pode advir da exibição dos cabelos. A roupa, neste caso, cumpre um duplo papel: cobrir todo o corpo, ocultando qualquer marca de sensualidade e, ao mesmo tempo, demarcar e classificar a propriedade do Estado sob o invólucro daquela que é capaz de procriar: 
tudo, exceto a touca e grandes abas ao redor de minha cabeça, é vermelho: da cor do sangue, que nos define. A saia desce à altura de meus tornozelos, rodada, franzida e presa a um corpete de peitilho liso que se estende sobre os seios, as mangas são bem largas e franzidas. As toucas brancas também seguem o modelo padronizado; são destinadas a nos impedir de ver e também de sermos vistas. (ATWOOD, 2017, p. 16)

Todo esse paramento visa demarcar a mulher que pertence ao Estado e que, por isso mesmo, não deve ser desejada por ninguém e somente deve ser tocada por aqueles homens que as podem "possuir" enquanto elas não engravidam e dão à luz, quando então, são encaminhadas para outra família abastada, onde novamente cumprirão o dever "sagrado" de procriar até que se tornem dispensáveis. Essa demarcação coloca em evidência a luta pela posse dos corpos femininos em via de mão dupla, as esposas devem ser virtuosas e silenciosas e as aias, silenciosas e eficientes para a reprodução, pois

qualquer corpo de mulher que não é apropriado, guardado e defendido por um proprietário cujo direito é baseado na filiação e na aliança e cuja utilização sexual que faz dela ou faz fazer é orientada para a procriação, pertence potencialmente a qualquer homem cuja pulsão sexual está por satisfazer. (HÉRITER, 2002, p. 201)

Depreende-se daí que o corpo feminino passa a ser visto como fonte inesgotável de procriação e de prazer, o que apenas reforça o velho paradigma da sociedade patriarcal de apropriação do corpo e da fecundidade feminina. Neste movimento, há uma dupla designação: todas as mulheres são submissas, mas algumas serviriam ao propósito de manutenção da família patriarcal, destinando-se ao casamento e à reprodução, como as esposas e aias do romance em estudo, e outras que serviriam ao prazer, como é o caso das casas de prostituição totalmente escondidas, posto que um estado teocrático e totalitário não admitiria a volúpia e a luxúria nem mesmo aos homens.

Essa designação de papéis sociais reforça um estereótipo social de homem, de mulher e de relações sociais que Damatta (1991) descreve como uma relação 
que se forja entre a casa e a rua e coloca em choque a instituição família, a partir de seu princípio religioso, e as práticas sociais e "sexuais" que subvertem essa moral em face dos interesses próprios. No que concerne às práticas sexuais, é válido ressaltar que, no romance em estudo, embora o sexo não associado à procriação seja classificado como imoral e criminoso e condenado com pena de morte, existem casas de prostituição social e politicamente encobertas, denominadas “a casa de Jezebel” (ATWOOD, 2017, p. 296) - nas quais as próprias Aias poderiam ser confinadas quando deixassem de servir aos interesses do Estado, isso se não fossem abandonadas nos campos de trabalho sob efeito de intensa radiação. O nome é uma clara alusão à Jesabel ou Jezebel, personagem apresentada no Livro dos Reis como esposa do Rei Acab, de Israel, que, de acordo com a narrativa bíblica, tornou-se impuro e promíscuo quando "desposou ainda Jezabel, filha de Etbaal, rei dos sidônios, e chegou até a render culto a Ball, prostrando-se diante dele" (REIS, 16: 31, BÍBLIA, 2004, p, 388). Baal era considerado um dos principais deuses do panteão dos cananeus e render-lhe culto era resultado da atuação promíscua de Jezebel, descrita como sacerdotisa e profetisa influente que dominou o Rei Acab.

Cumpre esclarecer que, embora em O conto da Aia a casa de Jezebel seja um prostíbulo, a narrativa do livro dos Reis não a apresenta, em nenhum momento, como uma prostituta, porque a imagem mística de profetiza que a envolvia impedia esse tipo de associação, contudo, seu nome passou a ser associado a todo tipo de promiscuidade que degenerava o homem. Basta lembrar que o significado do nome Jezebel é traduzido como "Baal exalta" e associado à luxúria e aos vícios, tal como ocorre no romance em análise: “a comida não é má e tem bebida e drogas, se você quiser, e só trabalhamos à noite" (ATWOOD, 2017, p. 296).

Assim, a referência a Jezebel se constitui como um marco importante desse retorno ao passado revestido de ficção, pois a projeção distópica criada a partir 
desse referencial reflete o medo da retroação a um tempo em que mulheres eram punidas e mortas apenas por serem consideradas impuras e influenciadoras do pecado e eram categorizadas como mulheres da casa, destinadas ao casamento, ou mulheres da vida, as da rua, do pecado (DAMATTA, 1991). Mesmo em face dessa divisão, no romance em estudo, o sexo é tomado como sinônimo de pecado e entendido como algo que deve ser praticado visando apenas à procriação, motivo pelo qual mesmo a relação sexual com a mulher que é a esposa assume contornos diferenciados, pois sempre é condicionada pela moral religiosa.

Essa condição se aplica especialmente às Aias, que são trazidas para dentro de casa e são usadas sexualmente sempre sob a supervisão das esposas. Demarcadas como gado, essas Aias passam a ser objeto da cobiça masculina e de rejeição de todas as demais mulheres que não podem procriar, como se nota na passagem em que a narradora protagonista do romance em estudo se depara com a falta de gentileza das demais mulheres: “o cenho franzido não é nada pessoal contra mim: é o vestido vermelho que ela desaprova, e o que ele representa" (ATWOOD, 2017, p. 18).

A marca do vermelho como indicativo do sangue reprodutor perpassa todo o enredo, dividido em duas partes; na primeira delas, narrada pela própria protagonista, apresenta-se a vida de uma dessas Aias, Offred, literalmente, "de Fred", um dos dirigentes políticos de Gilead: "meu nome é Offred, tenho outro nome que ninguém usa porque é proibido. Digo a mim mesma que isso não tem importância, seu nome é como um número de seu telefone, útil para os outros; mas o que digo a mim mesma está errado" (ATWOOD, 2017, p. 103). Nota-se que o prefixo "of" tem a função de designar a ideia de pertencimento, tal como se denota no emprego de "de" do francês, de "von" no alemão, ou no sufixo "son" em sobrenomes de língua inglesa.

A segunda parte funciona como um epílogo, intitulado Notas Históricas sobre o conto da aia, na qual a voz narrativa é a de um professor de Cambridge que 
está apresentando sua pesquisa em um simpósio, no ano de 2195, sobre Estudos Gileadianos. Ao longo de sua fala, o leitor descobre que o conto da aia é uma transcrição de algumas fitas-cassete gravadas no período da República de Gilead. Essa segunda parte parece funcionar como um gatilho de verdade que permite verificar a autenticidade histórica da primeira narrativa por meio do cientificismo representado pelo professor.

Ao contrário do que possa parecer, esse gatilho não é um mero recurso estilístico de narrativa, pois funciona como um mecanismo de verificação da autenticidade do que se narrou, criando um efeito do real que, ao mesmo tempo em que certifica a narrativa, aponta uma experiência cujos precedentes são latentes, tanto na história, quanto na ficção. Em termos históricos, a aia reprodutora de uma sociedade pós-apocalíptica é facilmente associada a relatos da conquista e colonização das Américas e da África, contudo, o precedente mais recuperável aqui é a narrativa bíblica de Jacó, de suas esposas, Raquel e Lea, e de suas servas. Jacó é o provedor que lega 12 filhos homens a Israel, dentre os quais, os filhos de suas servas, que não podiam reclamá-los, por serem eles pertencentes às esposas e não às servas:

Raquel, vendo que não dava filho à Jacó, teve inveja de sua irmã: "dá-me filhos, disse ela ao seu marido, senão morro!". E Jacó irritou-se com ela. "Acaso, disse ele, posso eu pôr-me no lugar de Deus que te recusou a fecundidade?" Ela respondeu: “Eis minha serva Bala: toma-a. Que ela dê a luz sobre os meus joelhos e assim, por ela, terei também filhos". (GEN, 30: 13, BÍBLIA, 2004, p, 77)

Nota-se em O Conto da Aia uma releitura política da história bíblica de Raquel e Jacob, cuja visão patriarcal e machista sustenta a ideia de uma escrava não mais sexual, não uma meretriz, mas uma reprodutora a serviço de uma elite. Na trama, o leitor descobre que o sexo é uma cena, não uma vivência, pois é negado como prazer e deve ser praticado visando apenas à reprodução tão esperada, já que as Aias não são fontes de prazer, são urnas depositárias: “somos 
para fins de procriação, não somos concubinas, garotas gueixas, cortesãs. Pelo contrário: tudo o que era possível foi feito para nos distanciar dessa categoria" (ATWOOD, 2017, p. 165).

Essa ideia do ato sexual como cena pode ser notada na noite em que o comandante fará sexo com a Aia: há uma cerimônia a ser cumprida que se inicia com a leitura de algumas passagens da Bíblia, como uma invocação da piedade divina pelo ato carnal que acontecerá. A leitura deve ser realizada apenas pelo esposo, como reforça Offred: "podemos ouvi-la lida em voz alta, por ele, mas não podemos ler" (ATWOOD, 2017, p. 107). Após a leitura, feita na presença da aia, da esposa, e das Marthas, cada qual com sua devida etiqueta de classificação servil demarcada pela cor da roupa: "uma mulher ajoelhada de vermelho, uma sentada de azul, duas de verde, de pé" (ATWOOD, 2017, p. 106), as Marthas, empregadas que vestem verde, são dispensadas e a esposa, envolvida pela pureza representativa do azul, se senta na cama de pernas abertas e a aia se deita entre suas pernas, também com as pernas abertas, obedecendo ao que foi dito por Raquel, a esposa de Jacob:

Acima de mim, em direção à cabeceira da cama, Serena Joy está posicionada, estendida. Suas pernas estão abertas, deito-me entre elas, minha cabeça sobre sua barriga, seu osso púbico sob a base do meu crânio, suas coxas uma de cada lado de mim. Ela também está completamente vestida. (ATWOOD, 2017, p. 114)

Nesta posição, o Comandante, futuro pai, não deve tocá-la com as mãos, tampouco, olhá-la para evitar qualquer demonstração de prazer ou de afeto durante o coito:

Minha saia vermelha é puxada para cima até minha cintura, mas não acima disso. Abaixo dela o Comandante está fodendo. O que ele está fodendo é a parte inferior de meu corpo. Não digo fazendo amor, porque não é o que ele está fazendo. Copular também seria inadequado porque teria como pressuposto duas pessoas e apenas uma está envolvida. Tampouco estupro descreve o ato: nada está acontecendo aqui que não tenha concordado 
formalmente em fazer. Não havia muita escolha, mas havia alguma, e isso foi o que eu escolhi. (ATWOOD, 2017, p. 115)

Essa cena bizarra é uma metáfora do princípio puritano de que a dignidade humana não pode ser maculada pelos desejos carnais, lógica da igreja cristã que destina a Deus o amor e concebe o sexo como atividade de reprodução. “O amor não é o que interessa" (ATWOOD, 2017, p. 261) era a lição ensinada às futuras aias e esposas no Centro Vermelho, escola de formação de meninas que não visava à escolarização em si, mas à aprendizagem da hierarquia e a obediência a ela, num sistema de retorno ao passado: "tudo o que fizemos foi pôr as coisas de volta, de acordo com a norma da natureza" (ATWOOD, 2017, p. 261).

A norma natural, neste caso, seria a de destinar à mulher a casa e, ao homem, a rua, reforçando o papel masculino como de progenitor e o feminino como o de procriador (DAMATTA, 1991). Além disso, coloca-se em evidência o papel categoricamente definido para todas as mulheres como bonecas nas mãos de homens: esposas de azul, aias de vermelho, empregadas de verde, tias de marrom e economoesposas com listras multicoloridas; todas a serviço da dominação masculina. Esta forma de se vestir implica um tipo de tratamento bem delimitado que retira toda individualidade feminina, inclusive no que toca à escolha da roupa e à subtração dos nomes de algumas mulheres.

No que tange à vestimenta, a narradora observa que "algumas pessoas chamam de hábitos, uma boa palavra para eles. Hábitos são difíceis de abandonar ou despir" (ATWOOD, 2017, p. 36). O hábito substitui a escolha individual tanto porque determina o modelo da roupa quanto a cor e, nesse particular, o uso de cores diferenciadas para identificar e classificar cada mulher segundo seu segmento social se torna uma estratégia de categorização que pode ser facilmente apreendida sem que, para isso, as mulheres precisem aprender a ler e a escrever. Essa mesma lógica é empregada também na designação do comércio em geral: 
A loja tem uma enorme insígnia de madeira do lado de fora, com o formato de um lírio dourado; chama-se Lírios do Campo. Pode-se ver o lugar, debaixo do lírio, onde o nome inscrito foi apagado, repintado e coberto por uma tarja de tinta, quando decidiram que mesmo os nomes de lojas eram tentação demais para nós. Agora os lugares são conhecidos apenas pelas figuras desenhadas nas insígnias em madeira. (ATWOOD, 2017, p. 36)

As iconografias, tal qual o uso de cores, compõem um conjunto bem delimitado de regras que banem da sociedade o exercício da leitura e vão minando as possibilidades, a autonomia social, a formação da identidade pessoal e toda e qualquer forma de resistência. Nesse sentido, a subtração dos nomes é outro elemento importante: as mulheres são tias, esposas, economoesposas ou marthas ou aias antes de serem reconhecidas pelo nome, primeira referência individual de identificação. É importante lembrar aqui, que, no caso do Brasil,

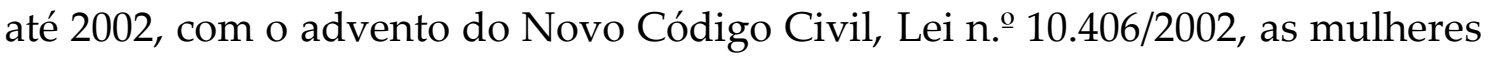
tinham que adotar e assumir o sobrenome do marido quando se casavam, culminando em uma espécie de apagamento identitário que abrangia desde o patronímico ao nome de família da mulher.

Na trama, esse apagamento identitário feminino e a manutenção de uma ordem em que, antes de ser alguém, se pertence a alguém, colocam em evidência a retroação a um contexto em que o Pater Famílias era o símbolo do poder marital que naturalizava a condição inferior da mulher e a perpetuação do patronímico do homem em detrimento dessa inferioridade. Esse poder era pautado na necessidade de uma direção unificada para matrimônio segundo a qual o marido era "o mais apto, pelos predicados do seu sexo, para exercê-lo" (PEREIRA, 1999, p. 106).

Essa mesma linha de raciocínio era empregada na definição de papéis calcados na natureza do sexo biológico, segundo a qual gestar e parir ainda são ações fundamentalmente humanas e femininas, daí a importância de manter as mulheres subjugadas, garantindo que a espécie possa se reproduzir de acordo 
com os interesses de quem determina o modus operandi de uma comunidade sob os holofotes da valência diferencial dos sexos e da dominação masculina (HÉRITIER, 2002). Essa conduta pode ser facilmente recuperável nas narrativas tradicionais dos grandes patriarcas bíblicos que punham em evidência a distinção entre casamento, procriação e prazer, bem como a disparidade de papéis sociais que passou a ser gradativamente incorporada e ontologicamente naturalizada, performando um discurso de distinção não apenas dos papéis sociais, mas do próprio ser feminino como inferior ao masculino. Tal discurso encontra seu fundamento na narrativa bíblica de Adão e Eva, na qual Eva é culpada pelo pecado original que macula a humanidade para todo o sempre por ter sido mais suscetível ao se deixar seduzir pelo mal. Essa narrativa, evidenciada nos primeiros capítulos do livro do Gênesis, apresenta a ambiguidade da mulher: ser que carrega o poder da procriação, mas que deve ser mantida sob controle para evitar maiores quedas além daquela do pecado original.

Convém ressaltar, no entanto, que a opção pelo bem ou pelo mal foi compartilhada solidariamente por Adão e, desde então, por incontáveis homens, daí o argumento de que a valência diferencial dos sexos foi algo construído a partir de um discurso de dominação que as narrativas bíblicas souberam explorar com veemência ao reforçar uma perspectiva androcêntrica mesmo em livros nos quais as mulheres desempenham papéis importantes, como Rute por exemplo.

As narrativas bíblicas reforçam o papel do grande pai provedor e da mulher fecunda que lega filhos às nações patriarcais. Embora muitas distopias clássicas apresentem caminhos científicos para a reprodução humana, nada pôde superar o processo gestacional feminino, nunca atingido pelo homem, daí a necessidade de controle.

A modernidade trouxe vantagens e desvantagens, gerando ambiguidades sociais e a esterilidade é uma dessas ambiguidades que alimentam o conflito narrativo em O conto da Aia. O movimento realizado pelas lideranças políticas de 
Gilead não só evidencia a intenção de criar um novo referencial identitário para o povo, que deve incorporar o recato e a ideia de sexo, ato físico, como algo realizado puramente com fins de reprodução, como desvela duas memórias paralelas: uma memória oficial que revela o discurso vigente e depende do controle como forma de consolidação histórica (LE GOFF, 1990) e outra memória particular, desvelada pelos desejos e curiosidades proibidas da Aia Offred, que atua como força contrária ao movimento de planificação e massificação executado em Gilead e, por isso mesmo, como foco de resistência.

Offred recalca suas inquietações ao mesmo tempo em que as alimenta em uma narrativa desconexa e, por vezes, desesperada de uma mulher aprisionada fisicamente em um quarto e em uma veste que funciona como uma armadura, mas também, subjetivamente, em memórias antigas de liberdade. Essas memórias oscilam entre a dimensão utópica de um tempo bom que lhe serve de base para contrastar o real que a cerca e a incongruência da atualidade. De toda forma, são memórias de liberdade que aparecem ao longo da narrativa como fragmentos de vida que ainda pulsam em meio ao cenário de absoluta perda de direitos. A protagonista chega a afirmar "penso sobre ter tanto controle" (ATWOOD, 2017, p. 35) e seu pensamento desvela, na verdade, o medo feminino do retorno a um passado de cerceamentos, o medo de uma retroação acerca das conquistas femininas que a projeção distópica criada por Atwood desvela.

\section{CONSIDERAÇÕES FINAIS}

A trama de O conto da Aia coloca em evidência uma tentativa totalitária de eliminar o passado e de homogeneizá-lo para garantir sua coerência com a ideologia vigente, conformando uma memória coletiva que modifica não apenas os fatos em si, mas aquilo que se fala sobre ele, o discurso. Em outros termos, “a 
memória coletiva é não somente uma conquista, é também um instrumento e um objeto de poder" (LE GOFF, 1990, p. 477).

O governo de Gilead procura apagar todas as memórias de um passado calcado na luta por espaços de atuação e modos de ser protagonizados por mulheres, para retomar o paradigma da mulher responsável pelo pecado original e completamente dependente da dominação e da categorização masculina. Sob essa perspectiva, a obra, de modo geral, parece funcionar como uma forma de retomar a tradição androcêntrica dos grandes impérios e dos patriarcas bíblicos e, ao mesmo tempo em que o faz, parece conclamar o leitor a negar e a resistir a esta retomada.

Para redefinir os meandros da memória, faz-se necessário apagar os rastros (RICOEUR, 1997) e disseminar novas informações e conteúdos simbólicos que viabilizem a alteração do passado. Evidencia-se, assim, uma sociedade na qual se extingue os arquivos que não interessam e se promove a popularidade de outros que atendam ao interesse do grupo no poder. Nessas sociedades, esses arquivos "não escaparam à vigilância dos governantes, mesmo se podem controlar esta memória tão estreitamente como os novos utensílios de produção desta memória, nomeadamente a do rádio e a da televisão" (LE GOFF, 1990, p. 477).

Nas sociedades autoritárias, como é o caso de Gilead, a identidade pessoal é delimitada pelos arquivos que o governo admite como legais e fica sempre circunscrita a tipos pré-estabelecidos e estáticos nos quais a expressão da subjetividade é negada e hostilizada em detrimento de um comportamento servil e submisso. Nesse pacote, percebem-se os ecos de um discurso religioso tradicional no qual a mulher recebe e carrega a culpa pela expulsão do paraíso, motivo para submetê-la a cerceamentos das mais diversas ordens. Na trama, essas coações começam com a impossibilidade de movimentação da conta bancária e vão avançando para formas cada vez mais cruéis de constrangimento 
moral, de perda da autonomia e da identidade pessoal, perfazendo uma mulher que está sempre à mercê da figura masculina e nunca pode se governar à sua vontade.

Uma sociedade em que há a prevalência do poder marital pautado nos fundamentos do Antigo Testamento não se configura apenas como um lugar utópico ou distópico, mas como um tempo distópico no sentido das lembranças de um tempo e do medo de retroagir a esse tempo. Em outras palavras, utopia e distopia são vocábulos que se pautam na palavra grega "topos", que designa originalmente um lugar, neste caso, um lugar ideal, pseudo-geográfico, que não está no agora, mas que deverá ser construído no futuro. No caso da utopia, essa construção ideal sempre carrega resquícios do passado reafirmados no futuro, como se buscou apontar ao longo deste estudo e, no caso da distopia, o lugar que se entrevê no futuro deve ser evitado, pois ressignifica uma espécie de continuidade dos aspectos negativos que operam no presente e que podem conduzir a sociedades despóticas caso não sejam obstruídos.

Esses lugares, justamente por serem pseudo-geográficos, como é Gilead de O Conto da Aia e a ilha de Utopia de Morus, não podem ser substancialmente identificados no espaço, no topos, mas podem ser facilmente encontrados na memória das conquistas individuais e coletivas ou, no caso da aia narradora, das perdas que surgem acompanhadas do medo do retorno às situações de dependência que as mulheres já vivenciaram no passado.

A distopia permite antever um futuro sob a ótica dos acontecimentos já passados e por isso mesmo aponta para fragmentos da memória histórica ressignificada na ficção.

\section{REFERÊNCIAS}

ARENDT, Hannah. Origens do totalitarismo: antissemitismo, imperialismo, totalitarismo. Trad. Roberto Raposo. 4. ed. São Paulo: Companhia das Letras, 2012.

ATWOOD, Margaret E. O conto de Aia. Trad. Ana Deiró. Rio de Janeiro: Rocco, 2017. 
BÍBLIA. Português. Bíblia de Jerusalém. São Paulo: Paulus, 2004.

CANDIDO, Antônio. Literatura e Sociedade: Estudos de teoria literária e de história literária. 8. ed. São Paulo: T.A. Queiroz, 2000.

CLAEYS, Gregory. Utopia: a história de uma ideia. São Paulo: Edições SESC SP, 2013.

DAMATTA, Roberto. Espaço, cidadania, mulher e morte no Brasil. 4. ed. Rio de Janeiro: Guanabara Koogan S.A., 1991.

FERNÁNDEZ PRIETO, Celia. Poética de la novela histórica como género literario. In: Signa. Revista de la Asociación Española de Semiótica. Núm. 5, 1996, pp. 185-201.

FROMM, Erich. Posfácio (1961). In: ORWELL, George. 1984. São Paulo: Companhia das Letras, 2009.

HALBWACHS, Maurice. A memória coletiva. Trad. Laurent Léon Schaffter. São Paulo: Editora Revista dos Tribunais, 1990.

HÉRITIER, Françoise. Masculino Feminino II: dissolver a hierarquia. Lisboa: Instituto Piaget, 2002.

JACOBY, Russell. O fim da Utopia. Rio de Janeiro: Record, 2001.

LE GOFF, Jacques. História e Memória. Trad. Bernardo Leitão et al. Campinas, SP Editora da UNICAMP, 1990.

PESAVENTO, Sandra J. Fronteiras da ficção: diálogos da história com a literatura Discurso histórico e narrativa literária. In: Anais do XX Simpósio Nacional de História ANPUH. Florianópolis, julho 1999.

PEREIRA, Rodrigo da Cunha. Direito de Família: uma abordagem psicanalítica. 2. ed. Belo Horizonte: Del Rey, 1999.

RICOUER, Paul. Tempo e narrativa. Trad. Roberto Leal Ferreira. Csmpinas, SP: Papirus, 1997. Vol III.

RICOUER, Paul. Le memóire saisie par l'histoire. In: Revista de Letras, Universidade Estadual Paulista, v. 43, n. 02, jul/dez 2003. PP 15-28. Número especial sobre memória e literatura.

Nota do editor:

Artigo submetido para avaliação em: 03 de março de 2021.

Aprovado em sistema duplo cego em: 09 de julho de 2021. 